\title{
DOSE OPTIMIZATION WITH PITUITARY GLAND HORMONE FOR INDUCED BREEDING OF BATA FISH (Labeo bata)
}

\author{
M. I. Miah', A. A. Mamun' ${ }^{2}$ M. M. R. Khan ${ }^{3}$ and M. M. Rahman ${ }^{4}$
}

\begin{abstract}
An experiment on induced breeding of bata fish (Labeo bata) was carried out to determine the optimum dose of pituitary gland hormone. The present study consisted of four treatments namely $T_{I}, T_{2}, T_{3}$, and $T_{4}$ with three replications of each. Twenty-four pairs of male and twelve pairs of female were selected from the brood rearing ponds and the average body wt of the female and male were $390 \pm 10$ and $258 \pm 9 \mathrm{~g}$ respectively. To observe the effective dose for induced breeding, the females were first injected at the rate of $0.5\left(\mathrm{~T}_{1}\right), 1.0\left(\mathrm{~T}_{2}\right), 1.5\left(\mathrm{~T}_{3}\right)$ and $2.0\left(\mathrm{~T}_{4}\right) \mathrm{mg}$ PG/kg body wt. while the second doses were performed at the rate of $4.0\left(\mathrm{~T}_{1}\right)$, $4.5\left(\mathrm{~T}_{2}\right), 5.0\left(\mathrm{~T}_{3}\right)$, and $5.5(\mathrm{~T} 4) \mathrm{mg}$ PG/kg body wt. after $6 \mathrm{~h}$ from the first dose. On the other hand the males were administered a single dose of $2 \mathrm{mg} \mathrm{PG} / \mathrm{kg}$ body wt. at the time of second dose of the female. The ovulation rate, fertilization rate, hatching rate and survival rate were determined. Among the four treatments $\mathrm{T}_{2}(1.0 \mathrm{mg} \mathrm{PG} / \mathrm{kg}$ body wt. $)$ showed the best result in terms of ovulation rate $(89 \%)$, fertilization rate $(84 \%)$, hatching rate $(85 \%)$ and survival rate $(84 \%)$. The dose of $1.0 \mathrm{mg} \mathrm{PG} / \mathrm{kg}$ body wt. can be used in induced breeding of bata fish (L. bata) for the development of hatchery propagation.
\end{abstract}

Key words : Dose, Pituitary gland, Induced breeding, Labeo bata

\section{Introduction}

In the recent years the gap between supply and demand of fish is increasing with increased human population without concomitant increase in fish production (Ara, 1998). Supply of fingerlings is a prerequisite for the development of aquaculture (Webber and Riordan, 1976). By the course of time, natural spawning grounds of carps are threatened due to the construction of irrigation and flood control dams, river pollution and increased use of pesticides for growing high yielding varieties of rice and consequently the quantity of fry, obtained from the natural spawning grounds is declining and not able to meet the fish fry demand.

L. bata is one of the important minor carps in Bangladesh with great demand as good table fish. It belongs to the family cyprinidae. The $L$. bata has a great demand owing to its deliciousness, flavor and less spine. The natural environment is very suitable for its culture in Bangladesh. This species is an important source of proteins, fat, vitamins, minerals, iron, and calcium (Tripathi et al., 1997). In our country this fish grow well in ponds and ditches. It grows about 200-300 mm in length (Rahman, 1989). This species can be cultured by poly culture technique. A well established scientific data on

\footnotetext{
${ }^{1}$ Professor, Dept. of Fisheries Management, Bangladesh Agricultural University, Mymensingh-2202, Bangladesh

2 MS student, Dept. of Fisheries Management, Bangladesh Agricultural University Mymensingh-2202, Bangladesh

${ }^{3}$ Associate Professor, Dept. of Fisheries Biology and Genetics, Bangladesh Agricultural University, Mymensingh-2202, Bangladesh

${ }^{4}$ Ph.D. Fellow, Dept. of Fisheries Management, Bangladesh Agricultural University, Mymensingh-2202, Bangladesh
}

(Received : April 27, 2008) 
induced breeding may provoke the hatchery owner to produce seed of $L$. bata in their hatcheries that can meet the demand for supply of $L$. bata seed for culture and make the indigenous fish sustainable in its natural habit. Therefore, the present work is undertaken to determine the optimum dose of PG hormone.

\section{Materials and Methods}

The major part of the experiment was conducted at the Hatchery of the Field Laboratory Complex, Faculty of Fisheries, Bangladesh Agricultural University, Mymensingh. The experiment was done from 15 June to 1 August 2006.

\section{Collection of fish}

About $200 \mathrm{~L}$. bata both males and females were collected from the Jamuna river near Sirajgonj district. Collected fish were stocked in the previously prepared pond during November-December 2005. They were selected for brood stocking considering size, shape and colour.

\section{Brood rearing}

The brood fish of $L$. bata were reared in rectangular ponds of size $18 \times 14 \mathrm{~m}^{2}$ and an average depth of $1.3 \mathrm{~m}$, situated in the area of Field Laboratory complex of Fisheries Faculty. Special dieting was initiated in early March and continued up to the completion of breeding activity up to August 2006. Special feed enriched with protein and vitamin E was formulated which enhances the gonadal maturation in fishes. The ingredient and proximate composition of feed are shown in Table 1. The feed was supplied at $5 \%$ body wt. of the brood fish two times a day at $0900 \mathrm{~h}$ and $1700 \mathrm{~h}$ respectively. The feed used during the period of brood management was analyzed to know their proximate composition (Table 1) (AOAC, 1980). Regular manuring with cowdung was done at 15 days interval (a) $1235 \mathrm{~kg} / \mathrm{ha}$. and fertilization was done with Urea and TSP @ $49 \mathrm{~kg} / \mathrm{ha}$. and @ $24 \mathrm{~kg} / \mathrm{ha}$. respectively. Liming was performed whenever necessary@247 kg/ha.

Table 1. Ingredients and proximate composition of feed supplied to the brood fish of $L$. bata

\begin{tabular}{|l|c|c|c|}
\hline \multicolumn{1}{|c|}{ Ingredients } & Percentage & Proximate composition & Percentage \\
\hline Fish meal & 18.43 & Moisture & 10.16 \\
Rice bran & 18.43 & $\mathrm{CP}$ & 29.49 \\
Wheat bran & 18.43 & $\mathrm{CF}$ & 9.84 \\
Soya bean meal & 18.43 & $\mathrm{EE}$ & 18.17 \\
Mustard oil cake & 11.06 & $\mathrm{NFE}$ & 12.92 \\
Sesame oil cake & 11.06 & Ash & 19.42 \\
Wheat flour & 3.69 & & \\
Vitamin premix (Embavit) & 0.46 & & \\
Vitamin E & 0.01 & & \\
\hline
\end{tabular}

$\mathrm{CP}=$ Crude protein, $\mathrm{CF}=$ Crude fibre, $\mathrm{EE}=$ Ether extract, $\mathrm{NFE}=$ Nitrogen free extract

\section{Experimental design}

For induced breeding of $L$. bata, broods were collected from the brood rearing ponds of the Field Laboratory complex. In this experiment, four doses of $\mathrm{PG}$ hormone $0.5,1.0,1.5$ and $2.0 \mathrm{mg} / \mathrm{kg}$ 
Bang. J. Anim. Sci. 2008, 37 (1)

body wt. considered as treatments $T_{1}, T_{2}, T_{3}$ and $T_{4}$ respectively were used with three replications of each. For each treatment 12 males and 12 females were used. So 96 brood fishes were injected for induced breeding that composed of 32 females and 64 males. After ovulation, one female and one male were selected for stripping from each treatment. For dose optimization, ovulation rate, fertilization rate, hatching rate and survival rate was determined.

\section{Broad selection}

Healthy mature males and females were selected carefully. The average weight of the females and males were $390 \pm 10 \mathrm{~g}$ and $258 \pm 9 \mathrm{~g}$ respectively. The mature breeders were selected according to the following criteria in Table 2.

Table 2. Criteria followed to select mature breeders of $L$. bata

\begin{tabular}{|l|l|}
\hline \multicolumn{1}{|c|}{ Male } & \multicolumn{1}{|c|}{ Female } \\
\hline (a) Small in size & (a) Relatively large in size \\
(b) Abdomen normal; not bulky like female & (b) Abdomen bulging, elastic and soft \\
(c) Pectoral fins were rough & (c) Pectoral fins were slimy \\
(d) Slightly protruding reddish vent seemed \\
best criteria for male & (d) Small amount of eggs from the ovary were \\
\end{tabular}

\section{Conditioning}

Mature males and females from the brood rearing ponds were selected and immediately carried to the hatchery and kept into hapa in rectangular tank for about 24 hours. They were subjected to induce the breeding condition under water showering. No feed was provided during the period of conditioning.

\section{Collection and preparation of PG}

Locally available dry carp pituitary glands (PG) were collected from market in preserved condition in airtight vials were used as inducing agent. At first, the pituitary glands were gently removed from the vial with a pair of forceps and dried by using the filter paper for 2-3 minutes and then weighted by an analytical electronic balance (College B204-S, Switzerland).

The amount to be weight out was calculated on the total of the body weight of all the fishes using the following formula :

Weight of PG $(\mathrm{mg})=\frac{\mathrm{W}_{\mathrm{t}} \times \mathrm{P}_{\mathrm{t}}}{1000}$

Where, $\mathrm{W}_{\mathrm{t}}$ represents total body weight $(\mathrm{g})$ of all the fishes to be injected and $\mathrm{P}_{\mathrm{t}}$, represent the rate in $\mathrm{mg}$ PG to be injected $/ \mathrm{kg}$ body weight under a particular treatment. The weighed PG were transferred to a tissue homogenizer for thoroughly crushed. The crushed PG then diluted in distilled water to dissolve it and was centrifuged with a hand centrifuger for precipitation. The freshly prepared supernatant solution of hormone was then taken slowly in a $1 \mathrm{ml}$ hypodermic syringe for injection.

\section{Hormone administration}

After preparation of PG solution, it was injected in brood fish. Fish was caught carefully by net, and kept in sponge. They were covered by soft cloth; PG was then injected near the pectoral fin base (Fig. 3). The amount of PG solution for each fish was determined before according to the body weight 
of the broods. First dose of PG was administered to the female at 0600 h, at six hours interval; second dose of PG was given to female at $1200 \mathrm{~h}$ and first dose to male.

\section{Doses of PG for male and female broods}

In this experiment, four different doses of PG were applied. Table 3 shows the doses of different treatments.

Table 3. Doses of PG for male and female broods of $L$. bata

\begin{tabular}{|c|c|c|c|c|}
\hline Treatments & $\begin{array}{c}\text { First dose for female } \\
\text { (mg PG/kg body wt) }\end{array}$ & $\begin{array}{c}\text { Second dose for female } \\
\text { (mg PG/kg body wt) }\end{array}$ & Time interval (h) & $\begin{array}{c}\text { Single dose } \\
\text { for male }\end{array}$ \\
\hline $\mathrm{T}_{1}$ & 0.5 & 4 & 6 & 2 \\
$\mathrm{~T}_{2}$ & 1.0 & 4.5 & 6 & 2 \\
$\mathrm{~T}_{3}$ & 1.5 & 5.0 & 6 & 2 \\
$\mathrm{~T}_{4}$ & 2 & 5.5 & 6 & 2 \\
\hline
\end{tabular}

\section{Determination of ovulation rate}

The following formula was used to calculate the ovulation rate :

Ovulation rate $(\%)=\frac{\text { No. of fish ovulated }}{\text { Total No. of fish injected }} \times 100$

\section{Determination of fertilization rate}

The fertilization rate was determined by the following formula

Fertilization rate $(\%)=\frac{\text { No. of fertilized eggs } \times 100}{\text { Total No. of eggs (fertilized }+ \text { unfertilized }}$

\section{Determination of hatching rate}

Hatching rate was determined by the following formula

Hatching rate $(\%)=\frac{\text { No. of hatchlings }}{\text { Total No. of fertilized eggs }} \times 100$

\section{Determination of survival rate}

Five days old spawns of $L$. bata were stocked in glass aquarium (45 × $25 \times 24 \mathrm{CM})$ containing 17 liters of deep tube-well water in each. The experiment was designed with four treatments $\left(T_{I}, T_{2} T_{3}\right.$ and $\left.\mathrm{T}_{4}\right)$ and each treatment contained three replications $\left(\mathrm{R}_{\mathrm{I}}, \mathrm{R}_{2}\right.$ and $\left.\mathrm{R}_{3}\right)$ based on the larvae of four hormone treatments of $L$. bata. Sixty larvae of $T_{1}, T_{2} T_{3}$ and $T_{4}$ were used at a stocking density of 3.5 spawns/ $\mathrm{L}$ of the volume of water and were reared for 30 days. All other conditions during the experimentation were maintained in same condition. After completion of the experiment at $30^{\text {th }}$ day, the number of total live larvae in aquarium was counted separately for calculation of survival rate.

\section{Statistical analysis}

The results found in the experiment were subjected to statistical analysis, ANOVA, (one way) that showed the significance $(\mathrm{P}<0.05)$ level of differences between the treatments. This statistical analysis was performed with the aid of the computer software MS Excel program. Significant results $(\mathrm{P}<0.05)$ 
Bang. J. Anim. Sci. 2008, 37 (1)

were further tested using Duncan's New Multiple Range Test (DMRT) to identify significance differences among means. This statistical analysis was performed with the computer software MSTATC program.

\section{Results and Discussion}

\section{Brood stock management}

At the end of proper brood stock management the fish at the pond were found to be fully mature and ready to spawn. All of the fish did not mature at a time and first growing fishes were found to mature in early breeding season followed by others. During the experimental period temperature, $\mathrm{DO}$ and $\mathrm{pH}$ of water were recorded between $28^{\circ}$ and $32^{\circ} \mathrm{C}, 5.4$ and $7 \mathrm{ppm}$ and 6.8 and 7.7, respectively.

\section{Dose optimization with PG hormone}

Corresponding data representing the effects of PG doses on ovulation rate, fertilization rate, hatching rate and survival rate are shown in Table 4.

Table 4. Performances of different doses of PG on induced breeding of $L$. bata

\begin{tabular}{|c|c|c|c|c|}
\hline Treatments & $\begin{array}{c}\text { Ovulation rate (\%) } \\
\mathbf{M} \pm \text { SD }\end{array}$ & Fertilization rate (\%) & Hatching rate (\%) & Survival rate (\%) \\
\hline $\mathrm{T}_{1}$ & $66.67^{\mathrm{c}} \pm 16.67$ & $55.16^{\mathrm{c}} \pm 9.54$ & $58.09^{\mathrm{c}} \pm 4.32$ & $72.22^{\mathrm{bc}} \pm 2.55$ \\
$\mathrm{~T}_{2}$ & $88.89^{\mathrm{a}} \pm 9.62$ & $83.88^{\mathrm{a}} \pm 1.62$ & $85.71^{\mathrm{a}} \pm 2.86$ & $84.44^{\mathrm{a}} \pm 3.74$ \\
$\mathrm{~T}_{3}$ & $83.33^{\mathrm{b}} \pm 0.00$ & $73.25^{\mathrm{b}} \pm 9.60$ & $75.24^{\mathrm{b}} \pm 5.95$ & $70.56^{\mathrm{c}} \pm 0.96$ \\
$\mathrm{~T}_{4}$ & $88.89^{\mathrm{a}} \pm 9.62$ & $60.1^{\mathrm{bc}} \pm 9.64$ & $58.57^{\mathrm{c}} \pm 4.36$ & $69.44^{\mathrm{c}} \pm 0.96$ \\
\hline
\end{tabular}

${ }^{\text {abc }}$ Means in with different superscripts in each column differs significantly $(\mathrm{P}<0.05)$

\section{Ovulation rate}

Comparisons of the average ovulation rate with doses of PG are shown in Table 4 and Fig. 1. The highest average ovulation rate $(88.89 \%)$ was recorded in $T_{2}$ and $T_{4}$ whereas the lowest value $(66.67 \%)$ was found in $\left.\mathrm{T}_{1}\right)$. This is probably because they were treated in different doses. In a lower dose $67 \%$ ovulation rate indicate that the brood fishes were highly mature in the better brood stock management practice with special diet. The results indicated that there was a significant $(\mathrm{P}<0.05)$ difference among four doses of $\mathrm{PG}$ in the viewpoint of ovulation rate and revealed that $\mathrm{T}_{1}$ was significantly $(P<0.05)$ lowest than $T_{2}, T_{3}$ and $T_{4}$ but no difference between $T_{2}$ and $T_{4}$ while considering the ovulation rate. Chaudhuri (1960) have observed that induced breeding experiments yield better results when the donor and recipient fishes are of the same species. The differences in the results obtained between the trials could also be due to environmental factors and bad quality of pituitary glands.

\section{Fertilization rate}

During the experimentation with four treatments the average fertilization rate were recorded as 55.16, $83.88,73.25$ and $60.10 \%$ in treatments $\mathrm{T}_{1}, \mathrm{~T}_{2}, \mathrm{~T}_{3}$, and $\mathrm{T}_{4}$, respectively (4 and Fig. 2 ). The highest fertilization rate $(83.88 \%)$ ) was recorded in $\mathrm{T}_{2}$ whereas the lowest fertilization rate $(55.16 \%)$ was found in $T_{1}$. This is probably because they were treated in different doses of hormone treatments. Although some variations may arise due to physiological differences of the pair of fishers and also for 
experimental error. The results indicated that there was a significant $(\mathrm{P}<0.05)$ difference among four doses of $P G$ treatment $T_{2}$ was significantly $(P<0.05)$ higher than that of treatments $T_{1}$ and $T_{4}$.

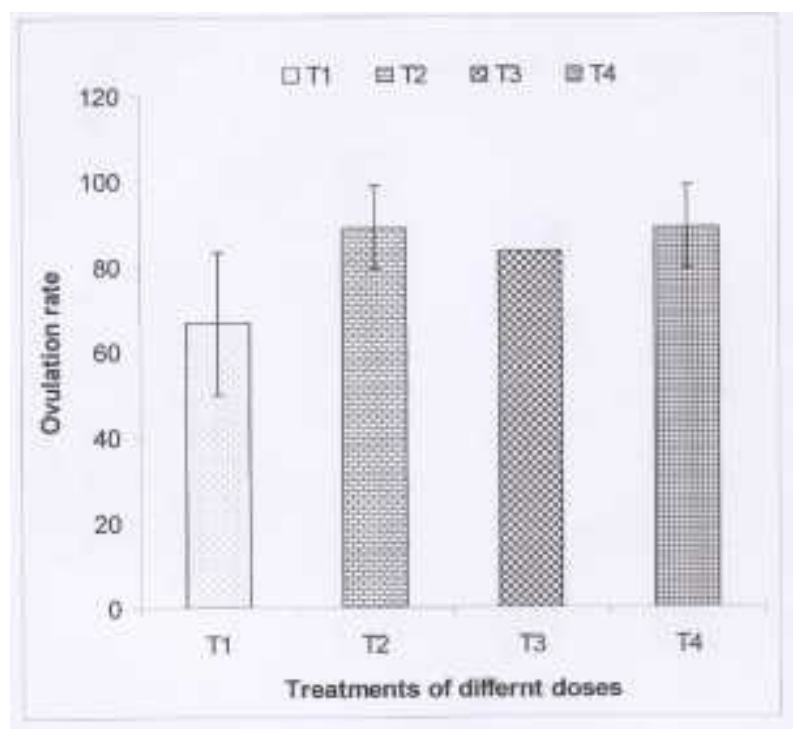

Fig. 1. Comparison of ovulation rate (\%) of $L$. bata during induced breeding of PG doses

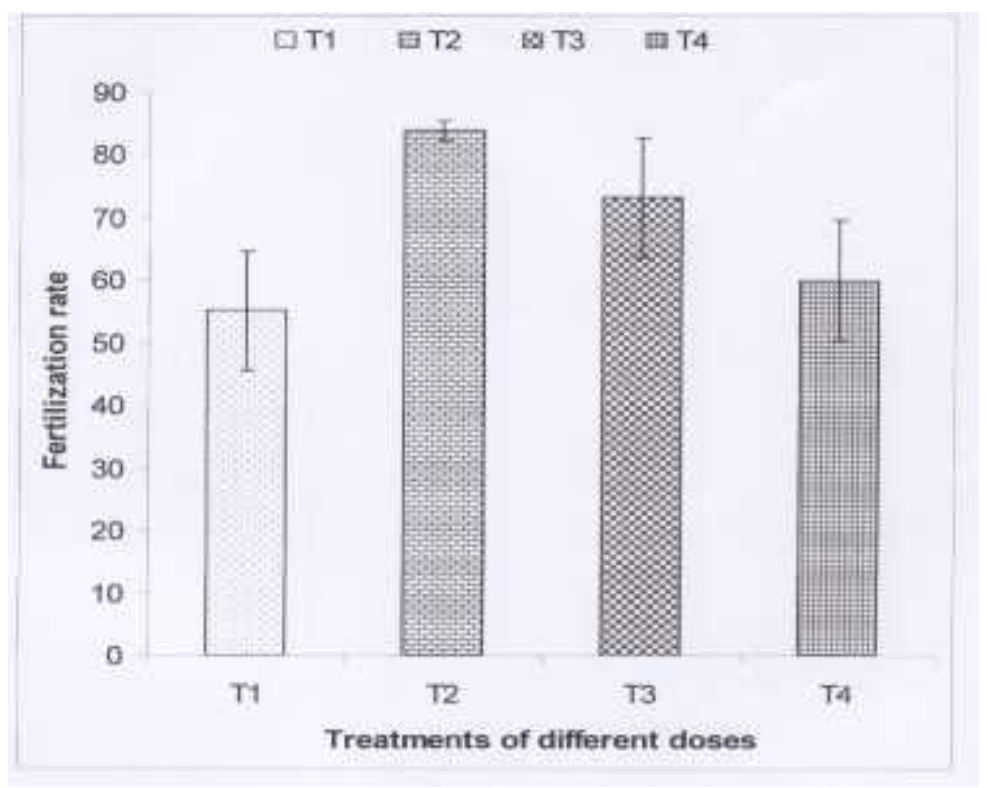

Fig. 2. Comparison of fertilization rate (\%) of $L$. bata during induced breeding of PG doses 
Bang. J. Anim. Sci. 2008, 37 (1)

\section{Hatching rate}

During the experimentation with doses of different treatments (Table 4) of L. bata the average hatching rate were found $58.09,85.7,75.24$ and $58.57 \%$ in treatments $T_{1}, T_{2}, T_{3}$ and $T_{4}$ respectively (Table 4 and Fig. 3). The highest hatching rate was recorded as $85.71 \%$ in $\mathrm{T}_{2}$ and the lowest hatching rate was recorded as $58.09 \%$ in treatment $\mathrm{T}_{1}$. The results indicated that there was a significant $(\mathrm{P}<0.05)$ difference among four doses of $\mathrm{PG}$. It was found that hatching rate in $\mathrm{T}_{2}$ was significantly $(P<0.05)$ higher than that of $T_{1}, T_{3}$ and $T_{4}$. The results $T_{1}$ and $T_{4}$ showed the worst value where there was no significant difference between them. Determination of hatching rate of fish is important for various respects. It can determine the status of how many fry can be produced from a number of fish and how many are lost and why. It helps to improved the hatchery product and thereby production.

\section{Survival rate}

The survival rate of $L$. bata larvae those were produced by four different hormone dose treatments (Table 3) were $72.22,84.44,70.56$ and $69.44 \%$ in $\mathrm{T}_{1}, \mathrm{~T}_{2}, \mathrm{~T}_{3}$ and $\mathrm{T}_{4}$, respectively after 30 days of experimental period (Table 4). The results revealed that there was a significant $(\mathrm{P}<0.05)$ difference among four doses of $P G$ and a significantly $(p<0.05)$ higher survival rate was observed in treatment $T_{2}$ compared to the other three treatments $\mathrm{T}_{1}, \mathrm{~T}_{3}$ and $\mathrm{T}_{4}$ respectively. Higher and lower doses of hormone resulted in low survival rate of hatching. Production of fish culture mainly depends on the survival rate of hatching.

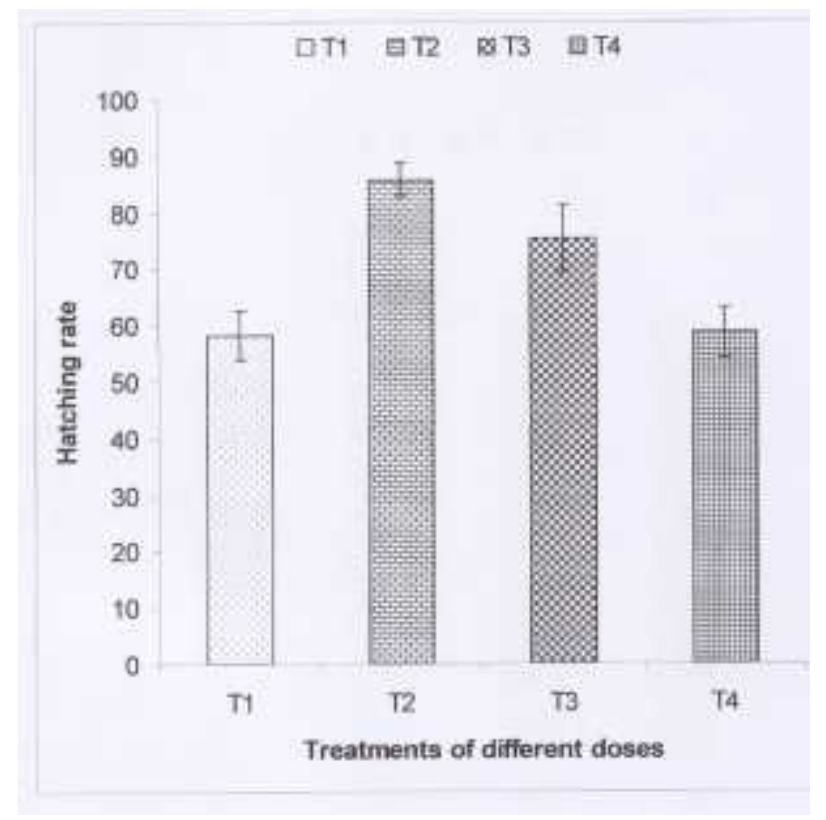

Fig. 3. Comparison of hatching rate (\%) of $L$. bata during induced breeding of PG doses

\section{Physico-chemical condition of water}

The physico-chemical condition such as temperature, dissolved oxygen and $\mathrm{pH}$ of water in experimental aquaria under different treatments with different larval stocks of $L$. bata ranged between 27 and $30.5^{\circ} \mathrm{C}, 6.0$ and $8.0 \mathrm{ppm}$ and 7.19 and 7.93 respectively with negligible variation. The range of 
temperature in which induced breeding of carps had been taken place was 24 to $31{ }^{\circ} \mathrm{C}$ and cool and rainy days had been found to be generally conduction to induced spawning (Chaudhuri, 1960). Which is similar to this experiment. Ahmed (1997) reported that the minimum water quality to maintain fish health should be $5 \mathrm{ppm}, 6.7-8.6,<3 \mathrm{ppm},<0.02 \mathrm{ppm}$ and $>20 \mathrm{ppm}$ for $\mathrm{DO}, \mathrm{pH}$, free $\mathrm{Co}_{2}$, ammonia and alkalinity respectively.

From the above discussion it can be said in short, that the ovulation, fertilization and hatching rate and also the survival rate of larvae differs mainly due to the hormone dose as well as brood stock management, quality of brood, quality of eggs, seasonal variation, incubation density, water flow during incubation, quality of hatchery water and handling procedure of the broods. But upon all consideration PG of $1.0 \mathrm{mg}$ as first dose and $4.5 \mathrm{mg}$ as second dose for per $\mathrm{kg}$ body weight may be recommended for induced breeding of $L$. bata in hatchery.

\section{Conclusion}

The present study can throw light for further researches on the improvement of artificial breeding of the fish concerning the optimization of hormone application, optimization of the environmental parameters and other biological aspects.

\section{Literature Cited}

Ahmed, A. T. A. 1997. Disease problems in carp and shrimp hatchery : Mr. Hasan, M. M. Rahman and Sattar (editors) Quality Assurance in Induced Breeding, Department of Fisheries, Jessore, Bangladesh. pp. 23.

Ananda, J. N. 1973. Experiment on induced breeding of Indian major carp by pituitary hormone injection in Uttar Prodesh. J. Inl. Fish. Soc. India, 5 : 37-45.

AOAC, 1980. Official Methods of Analysis. Association of Official Analytical Chemists. 13 ${ }^{\text {th }}$ ed., Washington DC, $1018 \mathrm{pp}$.

Ara, F. 1998. Determination of Fertilization and Hatching Rates of Different Culturable Species, M.S. Thesis submitted in Fisheries and Marine Resource Technology Discipline, Khulna University.

Atz, J. W. and Pickford, G. E. 1959. The use of pituitary hormones in fish culture. Endeavour, 18(71) : 125-129.

Chaudhury, H. 1960. Experiments on induced spawning of Indian carps with pituitary injections. Indian J. Fish., 7(1) : 20-48.

Hoque, M. M. 1990. Effects of different food on the gonadal maturation of some species of carps. A thesis submitted to the Department of Fisheries Biology and Limnology for M.S. degree in Fisheries Biology and Limnology. Bangladesh Agricultural University, Mymensingh. pp. 81.

Jhingran, V. G. and Pullin, R. S. V. 1990. A hatchery manual for the common Chinese and Indian major carps, Asian Development Bank. International Center for Living Aquatic Resources Management. pp. $1-58$.

Pillay, T. V. R. 1993. Aquaculture: Principles and Practices, 238 Main Street, Cambridge, USA. pp. $156-175$

Rahman A. K. A. 1989. Fresh water fishes of Bangladesh, The zoological society of Bangladesh, Department of Zoology, University of Dhaka. pp. 112-123

Tripathi, S. H., Roos, N. and Hasan, N. 1997. The role of small indigenous fish species in food and nutritional security in Bangladesh. NAGA News Letter, July-December. 13 pp.

Webber, H. and Riordan, P. F. 1976. Criteria for candidate species for aquaculture. pp. 23. 